\title{
RESUMO
}

DOI: $10.17564 / 2316-3801.2019 v 8 \mathrm{n} 3 \mathrm{p}^{2} 22-4$
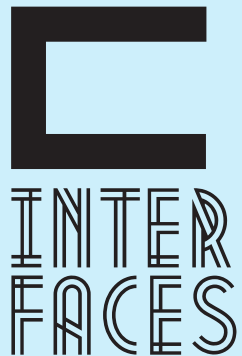

CIENTÍFICAS

\section{O ENSINO MORAL E CÍVICO COMO PRINCÍPIOS EDUCATIVOS NA FORMAÇÃO DOS CIDADÃOS}

MORAL AND CIVIC EDUCATION AS EDUCATIONAL PRINCIPLES IN TRAINING CITIZENS

LA EDUCACIÓN MORAL Y CIIVICA COMO PRINCIPIOS EDUCATIVOS EN LA FORMACIÓN DE CIUDADANOS
Thiago Passos Tavares ${ }^{1}$

Marlton Fontes Mota ${ }^{2}$

Dinamara Garcia Feldens ${ }^{3}$
Esta pesquisa objetiva identificar o ensino moral e cívico como princípios educativos na formação dos cidadãos e traz reflexões sobre o ensino jurídico, a partir de suas políticas, ações e diretrizes institucionais. Trata-se de uma pesquisa aplicada, com abordagem qualitativa na qual se utilizou como instrumento para levantamento dos dados a partir de uma consulta semiestruturada a livros e artigos científicos. Foram empregados procedimentos metodológicos pautados em estudos descritivos e exploratórios como: levantamento bibliográfico. Os resultados obtidos revelam que para que aconteça um real desenvolvimento humano, com progressos substanciais e significantes, torna-se necessária a melhoria na qualidade da educação, tendo em vista que números por si só não representam um verdadeiro progresso de uma nação e sim um falso desenvolvimento desta.

\section{PALAVRAS-CHAVE}

Aprendizagem. Direito. Didática. Educação. Ensino. 


\section{ABSTRACT}

This research aims to identify moral and civic education as educational principles in the education of citizens and brings reflections on legal education, based on their policies, actions and institutional guidelines. It is an applied research, with a qualitative approach in which it was used as an instrument to collect data from a semi-structured consultation of books and scientific articles. Methodological procedures based on descriptive and exploratory studies were used, such as: bibliographic survey. The results obtained reveal that for real human development to take place, with substantial and significant progress, it is necessary to improve the quality of education, given that numbers alone do not represent a true progress of a nation, but a false development.

\section{KEYWORDS}

Learning. Right. Didactics. Education. Teaching.

\section{RESUMEN}

Esta investigación tiene como objetivo identificar la enseñanza moral y cívica como principios educativos en la formación de ciudadanos y trae reflexiones sobre la enseñanza jurídica, a partir de sus políticas, acciones y pautas institucionales. Es una investigación aplicada, con un enfoque cualitativo en el que se utilizó como herramienta para recopilar datos de una consulta semiestructurada de libros y artículos científicos. Se utilizaron procedimientos metodológicos basados en estudios descriptivos y exploratorios tales como: encuesta bibliográfica. Los resultados muestran que para que se produzca un verdadero desarrollo humano, con un progreso sustancial y significativo, es necesario mejorar la calidad de la educación, ya que los números solamente no representan el verdadero progreso de una nación, sino su falso desarrollo.

\section{PALABRAS CLAVE}

Aprendizaje. Derecho. Didáctica. Educación. Docencia. 


\section{INTRODUÇ̧̃̃o}

Educação, na teoria é uma palavra que representa civilidade, mas na prática o que se percebe é uma situação muito diferente. Na verdade, o objetivo, que deveria ser a formação dos alunos, busca somente uma ocupação de cadeiras escolares, no sentido de formar mais profissionais para o mercado de trabalho, sem que haja preocupação com a qualidade da capacitação desses futuros profissionais e com a formação cívica, moral e constitucional deles. A política educacional adotada nas escolas, nas universidades, na prática é nada mais, nada menos, que uma resposta imediatista e incompleta no contexto social do desenvolvimento humano.

Desde o processo de alfabetização, do conhecimento das primeiras letras, vislumbra-se a carência de qualidade do ensino no Brasil, agravado pela ausência de condições elementares para a implementação de projetos e políticas públicas voltadas às mudanças necessárias à proposta de crescimento exponencial na formação de cidadãos, situações estas que decorrem, em regra, da má gestão pública e da falta de prioridades no setor educacional.

0 presente estudo visa estabelecer a proposta a um novo panorama para ensino moral e cívico na formação dos cidadãos, propondo a reintegração da educação cívica no plano de ensino das escolas como um princípio educativo, ou seja, como base para nortear perspectivas, direitos e deveres.

Invariavelmente, a proposta da inserção nas grades curriculares do ensino de moral e cívica nas escolas traz a memória recente de que a referida disciplina foi projetada pela ditadura militar no país, com o intuito de propagar e sustentar os valores morais consagrados naquele período da história do Brasil e esse tema será devidamente abordado na pesquisa, tendo em vista o fato de que os educadores de hoje, compreendem a presença do civismo na contextualização das disciplinas de direitos humanos.

Dentro desse contexto, questiona-se: Será que a ausência do ensino cívico moral e constitucional não faz falta na formação dos cidadãos? Pode-se dizer que somos um país democrático quando o ensino das leis maiores e norteadoras de direitos não se apresentam nos conteúdos básicos ministrados nas escolas e universidades?

Nesse sentido, a pesquisa, de forma elementar pontua destacar sobre a identificação dos principais aspectos que envolvem o fenômeno do ensino no país, na atualidade, revolvendo aspectos históricos, sugerindo políticas que apresentem um maior comprometimento com a qualidade do ensino e com a formação moral, ética, cívica e constitucional dos cidadãos. Embora, não se pretenda adentrar às bases curriculares das instituições de ensino, cumpre relacionar teoria e prática a respeito do tema central do artigo para melhor evidenciar os questionamentos sugeridos e, enfim, consolidar a análise da situação atual do país, visando propor a reflexão sobre os gastos públicos com educação, ensino cívico, moral, constitucional e a formação dos alunos vinculada à cidadania.

Decerto que, se evidenciam necessárias as ações mais efetivas por parte dos gestores públicos que possibilitem a revisão do cerne da educação moral, cívica e constitucional para compor os princípios basilares da educação básica, para que haja realmente uma cidadania, para que nossos futuros civis e profissionais desenvolvam as habilidades e atitudes necessárias para a vivência democrática, com uma formação digna e uma integração dos alunos com a comunidade. 
O presente estudo será baseado na realização de pesquisas bibliográficas sobre a situação atual do ensino básico no país, utilizando o método qualitativo, que possibilitará o conhecimento básico a respeito do tema, abordando-o sob o aspecto da importância da educação moral, cívica e constitucional na formação complementar de cidadãos.

Fatores históricos que interferem na predisposição de incluir a educação moral e cívica nos currículos escolares serão destacados no trabalho, com o intuito de possibilitar a reflexão do leitor ao tema.

\section{CIVISMO NO BRASIL DA CONTEMPORANEIDADE}

A educação no Brasil, de forma geral, parte de princípios cognitivos em seus processos educacionais, dedicando a finalidade da aprendizagem, focada no conhecimento e na inteligência dos alunos, deixando de lado o ensino cívico, constitucional, da moral ${ }^{4}$ e da ética ${ }^{5}$. De modo tradicional os indivíduos nascem, crescem, tornam-se adultos e não sabem o que significa ser um cidadão, qual o seu dever e quais os seus direitos.

Como poderá um cidadão exercer suas obrigações sem saber o significado de cidadania? Está aí um dos principais aspectos do qual é extremamente necessário o aprendizado do ensino cívico e constitucional como um princípio educativo, norteando o indivíduo moralmente para que possa não apenas se desenvolver, mas que também esteja ciente do seu papel em meio à sociedade em que habita.

O significado da palavra "civismo", de acordo com Ferreira (2010, p. 168) retrata a "devoção ao interesse público; patriotismo", sendo uma prerrogativa bastante propagada no período que compreendeu o chamado "regime militar" no Brasil, sendo, inclusive, descrito da seguinte forma: "a disciplina Educação Moral e Cívica foi um dos grandes projetos dos ditadores para construir valores na sociedade, adequados ao ideal de segurança nacional” (SANTOS VIEIRA apud GOES, 2015, p. 1).

A afirmação acima se justificou pelo fato de que durante praticamente todo o período de ditadura militar, no Brasil a educação moral e cívica foi bastante aplicada nos currículos escolares. Desde a sua criação por meio do Decreto-Lei n 869, de 12 de setembro de 1969, até o ano de 1993, registrou-se um período de 24 anos consolidados de educação cívica nas escolas em todos os níveis

\footnotetext{
4 A moral é um diálogo do eu com o eu. Aquilo que você se impõe e não se autoriza e, portanto, não tem a menor importância se há vigilância ou não. É a capacidade de transcender aos próprios instintos não por medo do olhar do outro, mas por você mesmo. A proliferação de radares de trânsito, por exemplo, se deve à falta de formação moral. Se todos tivéssemos condição de imprimir a velocidade adequada aos veículos, não precisaríamos deles. Logo, quanto mais repressão, menos moral (MELLO, 2014)

5 A ética tem de ser tratada por um prisma de paixões, de emoções e de sensações. Tenho a nítida impressão de que, toda vez que estamos diante de dilemas existenciais, é muito importante observarmos o duelo entre esperança e temor. Quer dizer, muitas vezes, temos a esperança de auferir bons resultados e até de minimizar custos e esforços com isso. Então, de um lado, a esperança é um ganho de potência a partir de uma situação imaginada que é vantajosa, prazerosa, que é boa, enfim. De outro lado, temos o temor, que é justamente o contrário, ou seja, o indivíduo se apequena diante de uma situação imaginada, diante de uma consequência nefasta que possa lhe acontecer. Muitas das atitudes indignas e desonrosas que observamos acabam sendo a vitória da esperança sobre o temor (CORTELLA, 2014).
} 
de ensino, do fundamental ao médio, ou seja, o que caracterizaria hoje o ensino básico. Mas, considerar a disciplina em questão como vinculativa ao regime ditatorial, com o devido respeito, seria tolher-lhe a essência de cidadania.

Segundo Costa (1991), a moral estabelece uma série de direitos e deveres com relação à nossas particularidades "moral individual”, se tratando de família "moral familiar", falando em sociedade "moral social”, com relação à Pátria "moral cívica” e a todos os povos "moral internacional”.

Atualmente, segue a educação em um novo momento, uma educação laica ${ }^{6}$, com base na democracia $^{7}$, porém sem ensino moral e cívico, que certamente agregaria valores de pertencimento do indivíduo com o seu país, enaltecendo o espírito de cidadania e melhor qualificando o ensino base. A qualidade é de extrema importância em qualquer organização, seja ela uma instituição de ensino ou não, independendo do ramo de atividade e abrangência de atuação, podendo ser voltada, tanto para o setor público quanto o privado. Seja lá qual for o porte da instituição, o que deve ser observado são os programas de qualidade e de melhoria nos processos.

Carvalho (2005), afirma que uma gestão de qualidade engloba um conjunto de atividades interligadas para dirigir e controlar uma organização de forma a conduzir o planejamento, consistindo em garantia e melhoria da qualidade. Qualificação essa que simplesmente não existe, está somente no papel, como muitas outras leis que não funcionam na prática. São necessárias ações por parte dos gestores que tragam de volta a qualidade do ensino e a educação moral, cívica e constitucional para que haja realmente uma cidadania, para que nossos futuros civis, também profissionais desenvolvam as habilidades e atitudes necessárias para a vivência democrática, uma formação digna, uma integração social e uma real capacitação para o mercado de trabalho, que tem ficado cada vez mais competitivo com o passar do tempo.

No caso de uma escola, o foco deve recair sobre os alunos, a razão de ser de toda instituição de ensino. Uma gestão de qualidade deveria: planejar, controlar e garantir a melhoria da estrutura e não deixar que fiquem precárias as condições de ensino, visando apenas o aumento da oferta de vagas. Antes de pensar em ampliar o número de pessoas atendidas ou de serviços prestados, primeiro deveria ser feito uma "arrumação da casa”, ou seja, melhorar aquilo que já existe.

Etapas como diagnóstico, correção, prevenção e melhoria devem ser essenciais para que uma instituição educacional mantenha condições mínimas de ensino, mas estas são praticamente ignoradas e o resultado é a precária estrutura física e consequentemente um ensino sem qualidade.

6 Para que a educação laica aconteça exige-se uma metodologia em sala de aula inovadora e interdisciplinar, acessível às mudanças de cada época, no lidar com o futuro de milhares de crianças, jovens e adultos. Para tanto, faz-se necessário que o educador compreenda a realidade educacional e que trace com os alunos o perfil histórico do conteúdo a ser trabalhado, conhecendo as suas origens (CUNHA, 2012)

7 A democracia tem sido especialmente bem sucedida na prevenção de calamidades que são fáceis de entender e nas quais a solidariedade pode atuar de uma forma particularmente imediata. Muitos outros problemas não são tão acessíveis assim. Por exemplo, o êxito da Índia na erradicação da fome coletiva não teve um correspondente na eliminação da subnutrição regular, na solução do persistente analfabetismo ou das desigualdades nas relações entre sexos. Enquanto é fácil dar um caráter político ao flagelo das vítimas da fome coletiva, essas outras privações requerem uma análise mais profunda e um aproveitamento mais eficaz da comunicação e da participação política - em suma, uma prática integral da democracia (SEN, 2010). 
Para os especialistas, um projeto político-pedagógico de uma universidade precisa ter compromisso mínimo com a qualidade do ensino e com formação dos cidadãos e não somente com a quantidade de vagas a serem ofertadas e o número de formandos ou aprovados em certames públicos.

Aborda Sandel (2011), que uma sociedade justa requer um forte sentimento de comunidade, necessita-se de formas para inserir nos cidadãos a preocupação com a coletividade, com o todo, dedicação ao bem social e comum. Não deve estar indiferente nas atitudes e disposições, aos "hábitos do coração" que os cidadãos levam para a vida pública, é preciso enxergar meios de se afastar de pensamentos meramente egoístas e exercitar um cultivo da virtude cívica.

A escola pública deixou de ser uma instituição para o desenvolvimento moral ${ }^{8}$ e cívico há quase vinte anos. Essa prática não está mais presente nas escolas, muito pelo contrário, tem se tornado precário o ensino público, com menos qualidade educacional. A responsabilidade do Estado perante a sociedade simplesmente deixou de ser praticada e o sentimento agora é de abandono e de injustiça.

\section{ENSINO JURÍDICO NO BRASIL}

O ensino do direito no Brasil foi formalizado e autorizado há aproximadamente 190 (cento e noventa) anos, pela Lei de 11 de agosto de $1827^{9}$, por Dom Pedro I, que escolheu como bases, o Estado de São Paulo e o de Pernambuco para sediar os primeiros cursos de educação jurídica do país.

Ocorre que, nos últimos cinquenta anos, tem se multiplicado a oferta de vagas para o curso de direito nas instituições de ensino superior do país. Isso se deve principalmente, ao incentivo dado pelos últimos governos, em capacitar profissionais para o mercado de trabalho, haja vista, ser o ramo jurídico, um leque de formação que possibilita tanto o ingresso em carreiras jurídicas de tribunais, como da magistratura, defensoria, advocacia, entre outros.

0 resultado disso encontra-se refletido no atual panorama educacional brasileiro, na qual, grande maioria das instituições de ensino superior, consideradas "máquinas de formar pessoas" funcionam a todo vapor. Críticas sobre o modelo da educação no Brasil são desferidas pelos profissionais educadores, que atribuem aos países subdesenvolvidos um processo de restrições à formação do homem pensante, assim dispondo:

Nunca pensou, contudo, o Autor, ingenuamente, que a defesa e a prática de uma educação assim, que respeitasse no homem a sua ontológica vocação de ser sujeito, pudesse ser aceita por aquelas forças, cujo interesse básico estava na alienação do homem e da sociedade brasileira. Na manutenção desta alienação. Daí que coerentemente se arregimentassem - usando todas as armas contra qualquer tentativa de aclareamento das consciências, vista sempre como séria ameaça a seus privilégios. È bem verdade que, ao fazerem isto, ontem, hoje e amanhã, ali ou em qualquer parte, estas forças destorcem

9 A lei de 11 de agosto de 1827 foi um gesto gigantesco, de 1828. “[...] A cidade brumosa amanheceu festiva. Os paulistas sentiam inchar-lhe os peitos de júbilo, envaidecidos com a escolha da capital da sua província para sede da primeira Academia de Direito do Brasil. Hontem a Independência, aqui, no Ypiranga, hoje a Academia, aqui, no convento de S. Francisco. Era um prenuncio lindo dos maravilhosos desdobramentos do futuro provinciano" (PORCHAT, 1927, p. 6). 
sempre a realidade e insistem em aparecer como defensoras do Homem, de sua dignidade, de sua liberdade, apontando os esforços de verdadeira libertação como "perigosa subversão", como "massificação”, como “lavagem cerebral” - [...]. (FREIRE, 2010, p. 44-45).

Por sua vez, a responsabilidade das universidades em preparar os profissionais para o mercado de trabalho tem se mostrado ineficaz, no sentido que, não por toda culpa destas, mais porque realmente inexiste mercado disponível para se trabalhar e a concorrência é gritante, na altura nada mais, nada menos que, aproximadamente 13.000 .000 (treze milhões) de desempregados.

Ademais, o ensino jurídico nas universidades, que adotam práticas de ensino bastante dogmáticas, por muitas vezes dissociadas ou divorciadas da realidade prática. Em alguns casos com o sentido de preparar o aluno para aprovação em exame da Ordem dos Advogados do Brasil e outros em direção a provimentos de concursos públicos.

Por sua vez, o ensino de moral e cívica no Brasil atual tem sido tema de discussões entre os educadores, que fazem os seguintes registros, a saber:

Desde que as disciplinas de Educação Moral e Cívica (EMC) e Organização Social e Política Brasileira (OSPB) foram oficialmente extintas, em meados dos anos 1990, temas como cidadania, ética e patriotismo entraram numa espécie de “limbo" nos currículos, ficando a cargo de cada unidade estabelecer como (e se) serão tratados. (O GLOBO, 2012, p. 3).

Nota-se que há um consenso entre os educadores de que o ensino deve fortalecer o vínculo do aluno com a sua cidadania, permitindo a construção de valores, dos quais devem perpassar o do pertencimento a sua região, ao seu país.

\section{A [IN] FORMAÇÃO CÍVICA NAS INSTITUIÇÕES DE ENSINO SUPERIOR BRASILEIRAS}

A condição elementar para a formação da cidadania do indivíduo não deve ser uma obrigação curricular restrita ao conhecimento passado pelas instituições de ensino superior, haja vista o amplo acesso às informações disponibilizadas pelas universidades no Brasil.

É fato inconteste que os professores de direito que lecionam educação jurídica nas universidades, de modo geral, não possuem formação para ensinar “direito", pois, inexiste o curso de licenciatura em direito no Brasil, apenas dispomos do curso de graduação em direito na modalidade bacharelado ${ }^{10}$, ou seja, o diplomado bacharel, que é preparado na universidade para atuar no mercado de trabalho. Diferente do que acontece

10 No que diz respeito ao bacharelado, percebe-se que a importância de um título (diploma acadêmico) não está relacionada somente com as mudanças inerentes ao ambiente competitivo no qual as organizações estão inseridas, tampouco, com o recente fenômeno da globalização de economias, sociedades ou culturas. No caso das organizações brasileiras, a importância de um título se explica, também, pela supervalorização de tal atributo herdada de nossos colonizadores portugueses que legitimavam o poder através dos títulos nobiliárquicos de barão, visconde, conde, marquês e duque e, na falta destes, dos acadêmicos de bacharel e de doutor (CRUZ, 2006). 
com os cursos de licenciatura ${ }^{11}$, que preparam o professor para o exercício do pleno do magistério.

Em uma direção semelhante, aborda a professora Mônica Teresa Costa Souza ao tratar do ensino jurídico no Brasil: “[...] têm sido feitas muitas críticas à qualidade do ensino jurídico no Brasil, seja no tocante aos métodos de ensino utilizados, aos conteúdos exigidos ou à sua capacidade de efetivamente preparar os bacharéis" (SOUZA, 2016, p. 96).

Aliado à afirmação acima, a formação da base cidadã de cada docente varia de acordo com a sua construção educacional e familiar, um exemplo textual se encontra na definição predita pelo superado Decreto-Lei 869/69, que no artigo $2^{\circ}$, afirmava:

Art. $2^{\circ} \mathrm{A}$ Educação Moral e Cívica, apoiando-se nas tradições nacionais, tem como finalidade: a) a defesa do princípio democrático, através da preservação do espírito religioso, da dignidade da pessoa humana e do amor à liberdade com responsabilidade, sob a inspiração de Deus;

b) a preservação, o fortalecimento e a projeção dos valores espirituais e éticos da nacionalidade;

c) o fortalecimento da unidade nacional e do sentimento de solidariedade humana;

d) a culto à Pátria, aos seus símbolos, tradições, instituições e aos grandes vultos de sua história;

e) o aprimoramento do caráter, com apoio na moral, na dedicação à família e à comunidade.

Decerto que a vinculação do ensino de educação moral e cívica à religiosidade traz diversas discussões na atualidade, haja vista a previsão constitucional sobre a liberdade de crença (art. $5^{\circ}, \mathrm{VI}$ ), que ante às liberdades filosóficas propagadas pelo sistema de ensino contemporâneo teria um embate para a sua consolidação perante os novos modelos.

0 processo de formatação de um novo cenário educacional que agregasse valores à formação cívica do indivíduo, a partir do seu ingresso nas universidades brasileiras, motivou diversos educadores à propositura de soluções, assim verificado:

No ensino superior a Educação Moral e Cívica era nomeada como Estudo de Problemas Brasileiros. Recebia um enfoque diferenciado, cujas construções de moral e civismo estavam atreladas ao aprofundamento sobre as questões sociais e econômicas do país, como forma de colaborar com a resolução de problemas, promovendo a evolução da sociedade e o progresso do país. (DOS SANTOS, 2016, p. 74).

Diversas propostas de congressistas foram verificadas por Amaral (2007, p. 2) a respeito da tentativa e do entendimento de que deveriam ser reinseridas nas ofertas curriculares das escolas, as disciplinas de Educação Moral e Cívica, Organização Social de Política Brasileira e os Estudos dos Problemas Brasileiros e a autora evidencia que:

Com a Lei de Diretrizes Bases da Educação Nacional n. 9.294/96 - LDB - e a divulgação

110 diploma de licenciado pelo ensino superior é o documento oficial que atesta a concessão de uma licença. No caso em questão, trata-se de um título acadêmico obtido em curso superior que faculta ao seu portador o exercício do magistério na educação básica dos sistemas de ensino, respeitadas as formas de ingresso, o regime jurídico do serviço público ou a Consolidação das Leis do Trabalho (CLT) (PANISSET, 2001). 
dos Parâmetros Curriculares Nacionais - PCN -, a discussão acerca da ética e cidadania tornou-se mais corrente, uma vez que tais documentos apontam esses termos como elementos-chave para a educação no país. Observa-se, nesse sentido, que as discussões que envolvem o conceito de ética, moral e civismo estiveram e ainda estão presentes no campo educacional, seja mediante disciplinas como Educação, Moral e Cívica; Organização Social e Política Brasileira; Estudo dos Problemas Brasileiros; pela via do Ensino Religioso, ou, mais recentemente, por meio dos temas transversais.

Notadamente a discussão sobre a importância da educação moral e cívica é minimizada quando da verificação da existência de disciplinas transversas que abrangem o tema, a exemplo das matérias alusivas à ética e cidadania, que embora tratem de abordagens mais amplas, possibilitam ao aluno a perspectiva de análise técnica e prática, por meio de estudos de casos. Mas, para os educadores a formação cívica, propriamente e direta analisada, não se notabiliza num grau mais específico que possa garantir uma compreensão mais dinâmica do indivíduo aos seus valores sociais, políticos e culturais, haja vista a miscigenação de informações permitida pelo leque de disciplinas que tratam da moral e cívica, em transversalidade.

Amaral (2007, p. 6) reitera sua preocupação em evidenciar as diversas discussões a respeito da importância da disciplina de Educação Moral e Cívica, chamando a atenção para que a temática não desvirtue a real proposta da inclusão, transformando-a num instrumento de abordagem para outros fins, assim predizendo:

Seria a inclusão de ética e da moral e cívica na escola um movimento disfarçado para ocupar o lugar do Ensino Religioso de forma obrigatória e não facultativa? [...] No entanto, a inclusão de uma disciplina sobre ética, moral e civismo obrigatória poderia, de maneira velada, ou não, abordar conteúdos de cunho religioso. A ética já é contemplada como tema transversal dos Parâmetros Curriculares Nacionais. Não como disciplina obrigatória, mas como parte de um conjunto de temas que integram o documento e que deveria perpassar todas as disciplinas.

O tema, portanto, está distante de encontrar um consenso, pois, a abordagem sobre valores éticos e cívicos poderão ficar à subjetividade do pensamento alinhado pela instituição escolar, ou mesmo do dirigente público, reafirmando os receios extraídos do período consentâneo àquele vivido durante o regime militar de 1964, que impunha os conceitos e os valores sociais, morais e cívicos à própria ordem advinda do então regime.

À diversidade e liberdade de expressões, a proposta para a formação moral e cívica inserida nos currículos escolares continuará enfrentando os desencontros da compreensão sobre o seu alcance, dada à fragilidade na concepção do seu cerne, pois, poderá ser alijado pelo pensamento político dominante, mesmo, sob os auspícios do ensino superior e dessa forma perpetuará o efeito dissonante entre a verdadeira cidadania e a sua formação basilar.

A respeito disso, cabe destacar que, quem está preocupado com renda e status, não para nem um segun- 
do para pensar em cidadania e em civilidade. Até porque, com a ganância ${ }^{12}$ de quem tem dois empregos, geralmente nem tempo tem para si mesmo, muito menos para os educandos e a formação ética e moral destes.

\section{CONSIDERAÇÕES FINAIS}

Dada à transversalidade aplicada por disciplinas outras que compõem os currículos escolares o tema debatido na pesquisa enfrenta grandes obstáculos para a sua implantação e diante das afirmações elucidadas no trabalho, de que a inserção da disciplina de Educação Moral e Cívica poderia proporcionar o desvirtuamento do seu real objetivo, que seria o de propiciar a melhor formação cívica do cidadão brasileiro, haja vista a permissibilidade que a referida disciplina traz no seu cerne, que poderia ser usada como instrumento de alienação religiosa ou política por parte dos gestores da educação.

Portanto, não se poderia atribuir que, somente por meio de uma educação cívica, moral e constitucional seria possível construir um real desenvolvimento para o país, pois, para consolidar essa afirmação se faz necessário um maior comprometimento com os gastos públicos em relação ao ensino no Brasil, além da urgente necessidade de estabelecer um plano de políticas públicas para a formação docente a respeito da temática, ora discutida, pois, o professor que teve sua formação cívica alicerçada nas escolas de ensino fundamental, certamente poderá propagar a sua experiência prática ao seu conhecimento teórico, dentro das prerrogativas estabelecidas para o projeto metodológico da educação moral e cívica, caso venha a ser implantado, sem deixar-se envolver pelo sistema político vigente ou pela influência religiosa.

Para que aconteça um real desenvolvimento humano, com progressos substanciais e significantes, torna-se necessária a melhoria na qualidade da educação, tendo em vista que números por si só não representam um verdadeiro progresso de uma nação e sim um falso desenvolvimento desta.

Com este artigo, espera-se que inicie o primeiro passo para que estudantes e universidades enxerguem aspectos norteadores de melhorias futuras no âmbito da educação pública e privada, para que as pessoas que vivem neste país possam avançar no seu lado moral, civil, educacional e acadêmico e não somente político e econômico.

\section{REFERÊNCIAS}

AMARAL, Daniela Patti do. Ética, moral e civismo: Duro Consenso. Cadernos de Pesquisa, 2007. Disponível em: http://www.scielo.br/pdf/cp/v37n131/a0737131.pdf. Acesso em: 13 maio 2017. CARVALHO, Marly Monteiro de. Gestão da qualidade: teoria e casos. Rio de Janeiro: Editora Elsevier, 2005.

CORTELLA, Mario Sérgio; FILHO, Clóvis de Barros. Ética e vergonha na cara. São Paulo: Papirus 7

12 A ganância é um defeito moral, um modo mau de ser, especialmente quando torna as pessoas indiferentes ao sofrimento alheio. Mais do que um defeito pessoal, ela se contrapõe à virtude cívica (SANDEL, 2011). 
Mares, 2014.

COSTA, Otto. Educação moral e cívica: ensino de primeiro grau. São Paulo: Editora do Brasil, 1991.

CRUZ, Breno de Paula Andrade. MARTINS, Paulo Emílio Matos. O poder do bacharel no espaço organizacional brasileiro: relendo Raízes do Brasil e Sobrados e mucambos. Cadernos EBAPE.BR, v. 4, n. 3, Rio de Janeiro, RJ, out. 2006. Disponível em: http://www.scielo.br/scielo.php?pid=S167939512006000300005\&script=sci_arttext\&tlng=es. Acesso em: 26 maio 2017.

\section{CUNHA, Clera Barbosa. Cláudia Barbosa. Revista da Associação Brasileira de História das}

Religiões - ABHR, v.1, p12-22, 2012. Disponível em: www.abhr.org.br/plura/ojs/index.php/anais/ article/view/675/562. Acesso em: 26 maio 2017.

DOS SANTOS, Marcia Regina. Escolarização das práticas. Moral, Civismo e educação no Brasil da década de 1970. XVI Encontro Estadual de História da ANPHU-SC. 2016. Disponível em: http://www.encontro2016.sc.anpuh.org/resources/anais/43/1464653592_ARQUIVO_ textocompletoampuh2016.pdf. Acesso em: 19 maio 2017

FERREIRA, Aurélio Buarque de Holanda. Mini Aurélio: o dicionário da língua portuguesa. Marina Baird Ferreira (coord.). 8. ed. Curitiba: Positivo, 2010.

FREIRE, Paulo. Educação como prática de liberdade. Rio de Janeiro: Paz e Terra, 2010.

MELLO, Raphaela de Campos. “Ser ético exercita o espírito”, diz Clóvis de Barros Filho. Editora Abril. 5 ago. 2014. Disponível em: http://casa.abril.com.br/bem-estar/ser-etico-exercita-o-espiritodiz-clovis-de-barros-filho/. Acesso em: 26 maio 2017.

\section{O GLOBO. Escolas ressuscitam, sem viés autoritário, parte do conteúdo de Educação Moral e}

Cívica e OSPB. Disponível em: https://oglobo.globo.com/sociedade/educacao/escolas-ressuscitamsem-vies-autoritario-parte-do-conteudo-de-educacao-moral-civica-ospb-14069887\#ixzz4iIWSAJTQ. Acesso em: 20 maio 2017.

PANISSET, Ulysses de Oliveira. Parecer CNE/CP28/2001. Ministério da Educação. Conselho Nacional de Educação. Educação Básica. 18 jan. 2002. Disponível em: portal.mec.gov.br/cne/ arquivos/pdf/028.pdf. Acesso em: 26 maio 2017.

PORCHAT, Reynaldo. O pensamento philosophico no primeiro século da Academia. Discurso do Dr. Reynaldo Porchat, na festa de Collação de Gráu e Centenario dos cursos jurídicos no Brasil (11 de agosto de 1927). Revista da Faculdade de Direito de São Paulo, v. 24, p. 333-374, 1928. 
SANDEL, Michael J. Justiça - o que é fazer a coisa certa. Rio de Janeiro: Civilização Brasileira, 2011.

SANTOS, Ana Cristina Bortoli Hildebrando dos. TREVISOL, Maria Teresa Ceron. Educação moral na escola: relato de experiências. Nuances: estudos sobre educação. Ano XVIII, v. 23, n. 24, p.122-141, set./dez. 2012.

SEN, Amartya. Desenvolvimento como liberdade. Tradução Laura Teixeira Mota. São Paulo: Companhia das Letras, 2010.

SOUZA, Mônica Teresa Costa. ROCHA, Felipe José Nunes. Do bacharelismo tradicional ao bacharelismo do século XXI: a deselitização da graduação em direito e o agravamento da crise do ensino jurídico no Brasil. Arquivo Jurídico, v. 3, n. 1. Teresina, 2016. 
1 Especialista em Direito Público - UNIESA; Pós-Graduado em Administração Pública pela Universidade Federal de Sergipe - UFS; Mestrando em Direitos Humanos na Universidade Tiradentes - UNIT; Mediador e Conciliador judicial na Justiça Federal do Estado de Sergipe; Advogado.

E-mail: admpublico@hotmail.com

2 Mestre em Educação pela Universidade Tiradentes UNIT; Doutorando em Educação - UNIT; Professor de Graduação e Pós-graduação em Direito da Universidade Tiradentes - UNIT; Especialista em Processo Civil; Advogado. E-mail: marltonmota@hotmail.com

3 Pós-Doutora pela Universidade Complutense de Madrid UCM, na área de Filosofia da Educação; Doutora em Educação pela UNISINOS na Universidade de Sorbonné; Mestra em Educação pela Universidade do Vale dos Rios dos Sinos - UNISINOS, Paris V, França; Licenciada em História (1996); Pesquisadora e professora da Universidade Federal de Sergipe - UFS. E-mail: dfeldens@hotmail.com

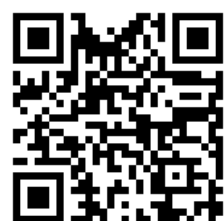

A autenticidade desse artigo pode ser conferida no site https://periodicos. set.edu.br

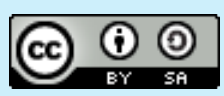

Este artigo é licenciado na modalidade acesso abertosob a Atribuição-Compartilhalgual CC BY-SA

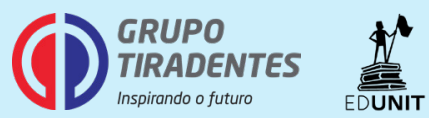

